\title{
KARAKTERISTIK KIMIA TEH KULIT MELINJO
}

\author{
${ }^{\mathbf{1} A r d i y a n s y a h,}{ }^{2}$ Mulia Apriliyanti \\ 1,2Program Studi Teknologi Industri Pangan Teknologi Pertanian Politeknik Negeri Jember \\ Jalan Mastrip Kotak Pos 164 Jember \\ ardiansyah87@gmail.com
}

\begin{abstract}
Abstrak
Dalam proses produksi industri emping melinjo, kulit melinjo sering dipisahkan dan dibuang sebagai limbah pertanian. Tujuan penelitian ini adalah mengolah dan mengetahui karakteristik kimia kulit melinjo menjadi teh. Proses pembuatan teh kulit melinjo dilakukan dengan oksidasi dan non oksidasi dengan waktu pelayuan 6, 8, dan 10 jam. Hasil karakteristik teh kulit melinjo yang diolah tanpa oksidasi enzimatis dengan waktu pelayuan 8 jam memiliki karateristik terbaik dengan kadar air 6,48\%, kadar abu 3,5\%, kadar fenol 34,8 \%, dan rendemen 56,9\%, dengan derajat kecerahan $37,93 \%$, nilai a 12,45 dan b 34,31.
\end{abstract}

Kata kunci: enzimatis, non enzimatis, kulit melinjo, teh herbal.

\begin{abstract}
In the process of industrial production of melinjo chips, peel of melinjo often separated as agricultural waste. The purpose of this research was to process and determine the chemical characteristics of peel of melinjo into herb tea. To production of herb tea from peel of melinjo is conducted by oxidation and non oxidation with a time of withering $6,8,10$ hours. The best treatment for processed peel of melinjo to herb tea is conducted without enzymatic oxidation until 8 hours, with moisture content of $6.48 \%$, ash content of $3.5 \%$, phenol content $34.8 \%$, and a yield of $56.9 \%$, with a degree of brightness $37,93 \%$, a* value of 12.45 and $b^{*}$ value of 34.31
\end{abstract}

Key words : enzymatic, herb tea, non-enzymatic, peel of melinjo

\section{PENDAHULUAN}

Tanaman melinjo (Gnetum gnemon) adalah tanaman penghasil buah melinjo dan jenis tanaman yang memiliki banyak manfaatnya, dari berbagai jenis tanaman gnetum, terdapat enam jenis tanaman yang dapat dimanfaatkan buahnya. Tanaman ini sudah sangat dikenal di seluruh Indonesia, karena hampir seluruh bagian dari tanaman melinjo ini sangat bermanfaat baik sebagai bahan makanan (bunga, buah, dan daun) maupun batang melinjo sebagai bahan perkakas rumah tangga. Dari hasil tanaman melinjo, biji melinjo yang sudah tua merupakan bagian yang mempunyai nilai ekonomi yang sangat tinggi, karena biji melinjo yang sudah tua merupakan bahan utama untuk membuat emping melinjo (Imelda, 2007).

Di Jawa, melinjo banyak ditanam untuk diambil daun, buah, dan bunganya. Salah satu produk dari tanaman melinjo yang telah di kenal secara luas di Indonesia adalah emping melinjo yang merupakan makanan khas Indonesia yang biasa dikonsumsi sebagai makanan ringan atau dapat dimakan bersama dengan nasi. Dalam proses produksi industri emping melinjo, kulit melinjo sering dipisahkan dan dibuang sebagai limbah pertanian. Berdasarkan hasil penelitian sebelumnya, kulit melinjo mengandung asam askorbat, tokoferol, dan polifenol memiliki aktivitas sebagai antioksidan juga berpotensi sebagai inhibitor xantin oksidase (Santoso dkk., 2010). Xantin oksidase memiliki peranan penting dalam proses pembentukan asam urat dengan mengkatalisis berturut-turut hipoxantin menjadi xantin kemudian asam urat.

Pengolahan teh dengan proses yang berbeda akan menghasilkan jenis teh yang berbeda pula, diantaranya yaitu teh hijau (diproses tanpa fermentasi/ oksidasi enzimatis) dan teh hitam (diproses dengan fermentasi/ oksidasi enzimatis penuh) (Suryaningrum et al., 2007). Proses pengolahan teh hijau meliputi pemilihan bahan baku, pelayuan, penggilingan, dan pengeringan. Proses pengolahan teh hitam meliputi pemilihan bahan baku, pelayuan, penggilingan, oksidasi enzimatis dan pengeringan. Terdapat perbedaan proses pengolahan teh hijau dan teh hitam yaitu pada proses oksidasi enzimatisnya (Sembiring, 2009) 
Pengolahan kulit melinjo menjadi teh merupakan upaya untuk memanfaatkan senyawa yang ada di dalamnya yang mampu memberikan karakter tersendiri untuk hasil teh tersebut. Oleh karena itu, peneliti perlu mengetahui karakteristik kimia hasil pengolahan teh kulit melinjo dengan perlakuan non enzimatis dan enzimatis.

\section{METODOLOGI}

Pelaksanaan penelitian dilakukan di Laboratorium Analisis Pangan Program Studi Teknologi Industri Pangan, Jurusan Teknologi Pertanian, Politeknik Negeri Jember.

A. Bahan dan Alat

Bahan baku dibutuhkan adalam kulit melinjo (Gnetum gnemon), aquades, bahan-bahan untuk analisa karakteristik kimia. Alat-alat yang digunakan adalah : blender, beaker gelas, botol kaca, cangkir, erlenmeyer, kain kasa, kertas saring, kurs porselen, labu ukur, mortar, muffle furnace, neraca analitik, oven, penangas air, pipet volume, buret.

\section{B. Metode pengolahan}

Perlakuan Oksidasi dan Non Oksidasi :

$\mathrm{O} 0=$ Tanpa Proses Oksidasi Enzimatis (Non Oksidasi)

$\mathrm{O} 1=$ Melalui Proses Oksidasi Enzimatis (Oksidasi)

Lama Pelayuan :

$\mathrm{T} 1=6 \mathrm{Jam}$

$\mathrm{T} 2=8 \mathrm{Jam}$

$\mathrm{T} 3=10 \mathrm{jam}$

Pelayuan dilakukan di atas jaring tipis, dibalik sebanyak 3 kali, dan diberi aliran udara menggunakan kipas angin. Pengecilan ukuran menggunakan blender, Oksidasi Enzimatis dilakukan menggunakan loyang pada suhu ruang $27{ }^{\circ} \mathrm{C}$ selama 135 menit. Pengeringan dilakukan dalam oven pada suhu $105^{\circ} \mathrm{C}$, selama 25 menit.

\section{Parameter Pengamatan}

1) Analisa kadar abu: Analisa kadar abu berdasarkan metode AOAC (AOAC, 2005).

2) Analisa kadar air: Analisa kadar air berdasarkan metode AOAC (AOAC, 2005).

3) Analisa Kadar Fenol (AOAC, 2005): Ditimbang sampel 0.5 gram kemudian dimasukkan dalam labu ukur volume $250 \mathrm{ml}$, ditambahkan larutan $\mathrm{NaOH} 10 \%$ hingga $\mathrm{pH}$ 10. Setelah itu, ditambahkan aquadest hingga tanda batas. Dipipet $25 \mathrm{ml}$ ke dalam erlenmeyer, dan ditambahkan 20 $\mathrm{ml}$ Brom 0,1 N, kemudian ditambahkan $5 \mathrm{ml}$ Asam Klorida dan segera ditutup. Dikocok kuat selama
30 menit.Ditambahkan secara cepat $5 \mathrm{~mL}$ larutan Kalium Iodida, dan ditutup serta dikocok dengan kuat. Kemudian sumbat dibuka dan dibilas dengan sedikit air dan dititrasi dengan Natrium Thiosulfat, yang sebelumnya ditambahkan dengan Indikator Kanji. Titrasi dihentikan sampai warna biru tepat hilang. Blanko menggunakan Aquades diperlakukan sama dengan sampel. Kadar fenol dihitung :

(Vblanko-Vsampel $\times N$ titran $x$ BE fenol )/ (mg sampel ) $x$ faktor pengenceran $\times 100 \%$

4) Analisa Fisik: analisa warna menggunakan chromameter, dan penentuan rendemen berdasarkan berat atau volume input dan output yang dihasilkan oleh proses ekstraksi. Rumus : rendemen $(\%)=$ teh melinjo/ kulit melinjo x $100 \%$

5) Analisa Data : Sampel yang digunakan adalah Kulit Melinjo. Penelitian ini menggunakan Rancangan Acak Kelompok (RAK) Faktorial dengan dua faktor yang terdiri dari dua taraf dan diulang sebanyak dua kali ulangan.

$\mathrm{i}($ ulangan $)=$ ulangan ke-i $(\mathrm{i}=1,2,3)$

$\mathrm{j}($ perlakuan $)=$ perlakuan ke-j $(\mathrm{j}=\mathrm{P} 1, \mathrm{P} 2, \mathrm{P} 3, \mathrm{P} 4)$

Data yang diperoleh diuji dengan analisis ragam (uji F) dan jika hasil uji $\mathrm{F}$ ada pengaruh perlakuan akan dilanjutkan dengan uji lanjut Duncan

\section{HASIL DAN PEMBAHASAN}

A. Analisis Karakteristik Kimia Teh Kulit Melinjo

Karakteristik kimia yang diamati pada penelitian ini meliputi kadar air, kadar abu, dan kadar fenol. Kadar air sangat mempengaruhi mutu teh kering, pada produk teh kering akan mempengaruhi umur simpan, dimana apabila teh kering mengandung cukup banyak kadar air akan mengakibatkan teh cepat lembab dan mudah rusak. Menurut SNI (1995), kadar air pada produk teh memiliki nilai maksimal $12 \%$. Dengan demikian kadar air yang dimiliki teh kulit melinjo memenuhi kategori kadar air teh yang ditetapkan oleh SNI. Rata-rata kadar air teh kulit melinjo dapat dilihat pada Gambar 1.

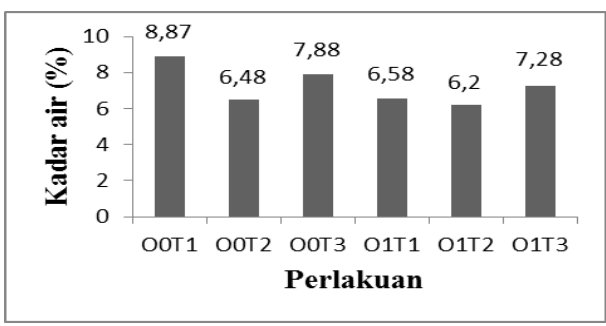

Gambar 1. Histogram kadar air teh kulit melinjo 
Teh kulit melinjo yang diolah melalui proses oksidasi enzimatis (O1) memiliki kadar air yang lebih rendah dibandingkan teh kulit melinjo yang tidak mengalami proses oksidasi enzimatis (O0). Tetapi pada pelayuan selama 10 jam kadar air meningkat dibandingkan dengan pelayuan selama 8 jam, baik tanpa enzimatis (O0T3) maupun oksidasi enzimatis (O1T3) hal ini disebabkan kulit melinjo dengan rentan waktu pelayuan yang lama semakin merusak kulit melinjo dan keluar air/lendir yang banyak sehingga kemampuan kipas angin untuk mengeringkan kurang begitu maksimal. Oleh karena itu, waktu pelayuan dan oksidasi enzimatis memiliki peranan penting sehingga tidak terjadi kebusukan.

Hasil analisis keragaman terhadap kadar air teh kulit melinjo menunjukkan bahwa perlakuan perbedaan proses oksidasi enzimatis (O) berpengaruh sangat nyata $(\mathrm{p}$ value $=0,0008)$ terhadap kadar air teh kulit melinjo, perbedaan waktu pelayuan (T) berpengaruh sangat nyata terhadap kadar air teh kulit melinjo ( $\mathrm{p}$ value = 0,0009), dan interaksi kedua perlakuan berpengaruh nyata terhadap kadar air kulit melinjo ( $\mathrm{p}$ value $=0,0006)$.

TABEL I.

UJI LANJUT BEDA JARAK NYATA DUNCAN (BJND) PENGARUH INTERAKSI PERBEDAAN METODE OKSIDASI ENZIMATIS DAN LAMA PELLAYUAN TERHADAP KADAR AIR (\%) TEH KULIT MELINJO

\begin{tabular}{|c|c|c|c|c|c|c|c|}
\hline \multirow{2}{*}{$\begin{array}{l}\text { perlaku } \\
\text { an }\end{array}$} & \multirow[t]{2}{*}{ rerata } & \multicolumn{5}{|c|}{ beda riel jarak $\mathrm{P}=$} & \multirow{2}{*}{$\begin{array}{l}\text { BNJD } \\
0,05\end{array}$} \\
\hline & & 2 & 3 & 4 & 5 & 6 & \\
\hline O1T2 & 6,19 & & & & & & $\mathrm{a}$ \\
\hline O0T2 & 6,48 & 0,29 & & & & & ab \\
\hline O1T1 & 6,58 & 0,1 & 0,39 & & & & $a b c$ \\
\hline O1T3 & 7,27 & 0,69 & 0,79 & 1,08 & & & d \\
\hline O0T3 & 7,88 & 0,61 & 1,3 & 1,4 & 1,69 & & de \\
\hline O0T1 & 8,87 & 0,99 & 1,6 & 2,29 & 2,39 & 2,68 & df \\
\hline $\begin{array}{l}\alpha \quad 0,05, \\
\operatorname{df}(6)\end{array}$ & & 3,46 & 3,58 & 3,64 & 3,68 & 3,68 & \\
\hline DMRT & & 0,47 & 0,49 & 0,5 & 0,5 & 0,5 & \\
\hline
\end{tabular}

Tabel I menunjukkan hasil uji lanjut BJND pada taraf 5\% mengenai pengaruh kombinasi perbedaan metode proses oksidasi enzimatis (O) dan perbedaan lama waktu pelayuan $(\mathrm{T})$ terhadap kadar air, hasilnya menunjukkan bahwa perlakuan O1T2, O1T1, O0T2 tidak memiliki perbedaan, O1T2 dan O1T3 memiliki perbedaan nyata dikarenakan kadar air kembali meningkat yang diakibatkan kulit melinjo sudah rusak atau banyak mengeluarkan air akibat proses oksidasi enzimatis yang tidak bisa hilang dengan kipas angin selama proses pelayuan, perbedaan tersebut bisa juga disebabkan kurang proses mekanik ketika membolak balik daun teh kulit melinjo sehingga air yang keluar teperangkap diantara bubuk teh kulit melinjo.

Kadar abu merupakan parameter yang menunjukkan banyaknya kandungan mineral dalam bahan. Kadar abu teh kulit melinjo tidak memberikan perbedaan yang signifikan. Kadar untuk teh pada umumnya adalah sekitar $7 \%$, sedangkan untuk teh kulit melinjo berada dibawahnya yaitu 3,5-4\% (lihat Gambar 2). Hal ini dikarenakan perbedaan jenis tumbuhan dan lingkungan hidupnya. Hasil analisis ragam perlakuan non dan oksidasi enzimatis tidak memberikan perbedaan yang nyata dalam kadar abu teh kulit melinjo yang dihasilkan $(\mathrm{p}=0,75)$. Lama pelayuan kulit melinjo tidak berpengaruh nyata terhadap kadar abu, dikarenakan pelayuan tersebut tidak menyebabkan keluarnya sebagian besar padatan terlarut (mineral) dari dalam sel kulit melinjo.

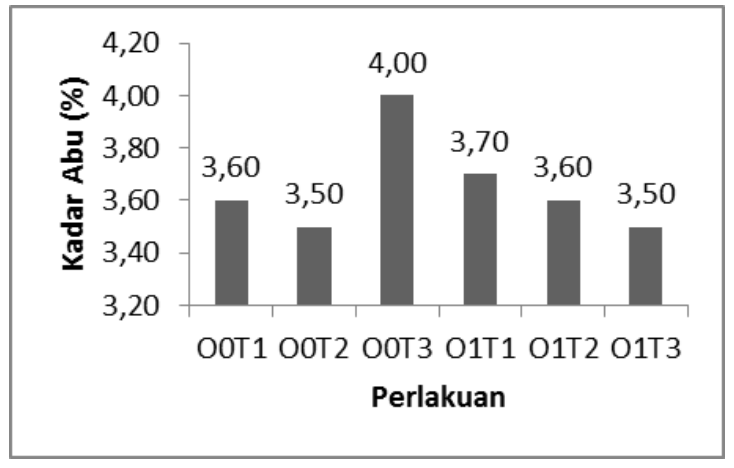

Gambar 2. Histogram kadar abu teh kulit melinjo

Senyawa fenol pada bahan makanan dapat dikelompokkan menjadi fenol sederhana dan asam folat. Semakin lama proses pelayuan sebenarnya terjadi proses perubahan biokimia senyawa yang terdapat pada kulit melinjo sehingga kadar fenol semakin menurun. Terjadi penyimpangan semakin tinggi waktu pelayuan dengan metode oksidasi enzimatis semakin meningkat yaitu 79,67 \%( lihat Gambar 3). hal ini disebabkan karena terjadi pembusukan dan senyawa yang dihasilkan dinggap senyawa fenol dengan metode titrasi thiosulfat. Oleh karena itu, perlu divalidasi dengan metode spektrofotometri untuk mengetahui benar senyawa fenol semakin meningkat.

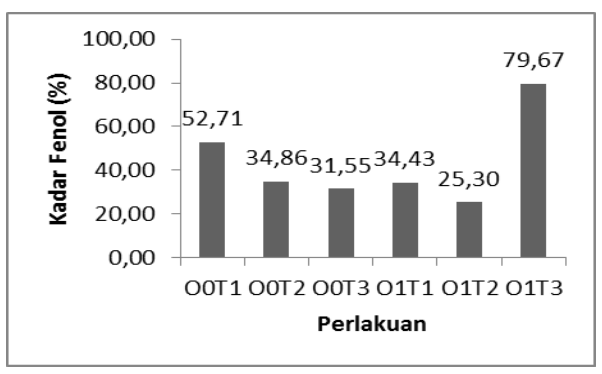

Gambar 3. Histogram kadar fenol teh kulit melinjo 


\section{B. Analisa fisik}

Warna bahan pangan dipengaruhi oleh kondisi permukaan bahan pangan dan kemampuannya untuk memantulkan, menyebarkan, menyerap dan meneruskan sinar yang nampak. Notasi L merupakan parameter kecerahan, notasi a adalah warna kromatik campuran merah dan hijau. Notasi b adalah warna kromatik campuran biru kuning. Derajat kecerhan menyatakan kemampuan suatu bahan untuk memantulkan cahaya yang mengenai permukaannya. Derajat kecerahan tertinggi pada perlakuan non enzimatis dengan pelayuan 8 jam 37,93. Notasi b bernilai positif yang menandakan semua sampel bewarna kekuningan. Nilai a bernilai positif yang menandakan sedikit kemerahan, dapat dilihat pada Tabel II.

$$
\text { TABEL II. }
$$

TOTAL COLOUR DIFFERENCE KULIT MELINJO PADA BERBAGAI VARIASI PERLAKUAN

\begin{tabular}{lllll}
\hline Perlakuan & Lightness & $\mathbf{a}$ & $\mathbf{b}$ & $\begin{array}{l}\text { Derajat } \\
\text { kecerahan }\end{array}$ \\
\hline O0T1 & 46,67 & 14,38 & 33,66 & 35,32 \\
O0T2 & 49,79 & 12,45 & 34,31 & 37,93 \\
O0T3 & 46,11 & 13,79 & 33,95 & 34,83 \\
O1T1 & 48,13 & 12,42 & 34,02 & 36,74 \\
O1T2 & 48,76 & 12,56 & 33,9 & 37,29 \\
O1T3 & 49,63 & 13,02 & 34,64 & 37,50 \\
\hline
\end{tabular}

Rata-rata nilai rendemen dari berbagai perlakuan sekitar $37 \%$ - 59\%, dapat dilihat pada Gambar 4 . Fungsi dari menghitung rendemen adalah mengetahui efisiensi suatu proses.

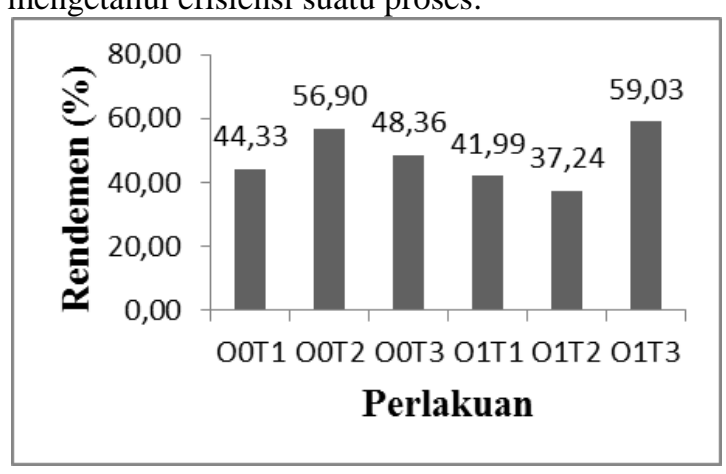

Gambar 4. Histogram rendemen teh kulit melinjo

\section{KESIMPULAN}

Teh kulit melinjo yang diolah tanpa oksidasi enzimatis (non oksidasi) dengan waktu pelayuan 8 jam yang memiliki karateristik terbaik dengan kadar air 6,48\%, kadar abu 3,5\%, kadar fenol 34,8 $\%$, dan rendemen $56,9 \%$, dengan derajat kecerahan $37,93 \%$, nilai a 12,45 dan b 34,31 .

\section{UCAPAN TERIMA KASIH}

Kami sampaikan terima kasih kepada pihak Politeknik Negeri Jember, khususnya Pusat Penelitian dan Pengabdian pada Masyarakat (P3M) yang telah menyelenggarakan dan mendanai program ini melalui Program Penelitian dan Pengabdian pada Masyarakat Sumber Dana BOPTN Tahun 2016.

\section{DAFTAR PUSTAKA}

Aditama, S. 1995. Mempelajari Sifat-Sifat Biji Melinjo (Gnetum gnemon, L) Selama Penyimpanan Dengan Menggunakan Gamping [skripsi]. Bogor: Institut Pertanian Bogor.

AOAC, 2005. Official Methods of Analysis. Assosiation of Official Chemist. Inc. Virginia.

Badan Standar Nasional. 1995. Standar Nasional Indonesia Teh.No.01-3836-1995. Departemen Perindustrian RI. Jakarta.

Budhiarso, S. 1981. Mempelajari Beberapa Sifat Fisik Buah Melinjo Dan Desain Alat Pengupas Kulit Biji Melinjo (Gnetum gnemon, L) [skripsi]. Bogor: Institut Pertanian Bogor.

Hambali E, M. Z Nasution, dan E. Herliana. 2005. Membuat Aneka Herbal Tea. Penebar Swadaya. Jakarta

Imelda, E, 2007. Karakterisasi Fisik dan Uji pH Larutan Rendaman Kulit Melinjo dan Kekerasan Kulit Melinjo [Skripsi]. Bogor: Institut Pertanian Bogor.

Kusumaningrum, Agus Supriadi, Siti Hanggita R.J. 2013. Karakteristik Dan Mutu Teh Bunga Lotus (Nelumbo nucifera). Vol 11. Jurnal Fistech. p :9-21

Santoso, M., Naka, Y., Angkawidjaja, C., Yamaguchi, T., Matoba, T. \& Takamura, H. 2010. Antioxidant and Damage Prevention Activities of the Edible Parts of Gnetum gnemon and Their Change upon Heat Treatment. Journal Food Science and Technology, 16 (6): 549-556.

Sembiring. 2009. Pengaruh kadar air bubuk teh hasil fermentasi. [Skripsi]. Universitas Sumatera Utara.

Suryaningrum, R.D., Sulthon, M., Prafiadi, S dan Maghfiroh, K. 2007. Peningkatan Kadar Tanin dan Penurunan Kadar Klorin sebagai Upaya Peningkatan Nilai Guna Teh Celup. Program Kreativitas Mahasiswa. Penulisan Ilmiah. Universitas Muhammadiyah Malang. 